\title{
The librarian 2.0: Identifying a typology of librarians' social media literacy
}

Journal of Librarianship and Information Science

The Author(

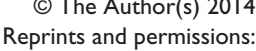

sagepub.co.uk/journalsPermissions.nav DOI: 10.1 177/0961000613520027

(SAGE

\author{
Hadewijch Vanwynsberghe \\ iMinds-MICT-UGent, Belgium
}

Ruben Vanderlinde

Ghent University, Belgium

Annabel Georges

iMinds-MICT-UGent, Belgium

Pieter Verdegem

Ghent University, Belgium

\begin{abstract}
This article reports on the identification of librarians' social media literacy profiles. These profiles were developed through the construction of scales measuring social media competencies. An online questionnaire was developed and administered to a sample of I 84 librarians working in Flemish public libraries. Cluster analysis revealed four social media literacy profiles: (I) social media workers; (2) social media laggards; (3) social media literates; and (4) social media spare-time users. This typology of social media literacy profiles is necessary information when developing a successful social media literacy strategy in libraries. Our research results further indicate that librarians who fit the social media literate or social media worker profiles are expected to play a central and facilitating role in the adoption and implementation of social media within public libraries.
\end{abstract}

\section{Keywords}

Library, library 2.0, profiles, social media literacy, social media use

\section{Introduction}

Online activities including engaging in blogs, social networking sites, photo- and video-sharing sites and locationbased services are a growing part of many people's private and professional lives. Social media is the unifying term for these 'new digital media phenomena [...] in which ordinary users (i.e. not only media professionals) can communicate with each other and create and share content with others online through their personal networked computers and digital mobile devices' (Bechmann and Lomborg, 2013: 767). Even though many studies elaborate on the potential of social media, it is difficult to locate an adequate definition.

According to Bechmann and Lomborg (2013), social media can be demarcated using three main characteristics.
First, social media communication is de-institutionalized, which means that media companies alone do not control the flow and distribution of information. Second, social media users are also information and content producers. We refer here to the collapse of production and consumption roles, labelled 'prosumer' (Jenkins, 2006) or 'produsage' (Bruns, 2008). Third, social media communication is interactive and networked in nature. Users interact with each other (rather than via institutions) and connect in a

\footnotetext{
Corresponding author:

Hadewijch Vanwynsberghe, iMinds-MICT-UGent, Korte Meer 7-9-II, Gent, 9000, Belgium.

Email: Hadewijch.Vanwynsberghe@ugent.be
} 
networked way. These social media, such as blogs, social networking platforms, wikis, collaborative tagging sites and sites enabling the sharing of content such as YouTube and Flickr, have gained substantial popularity in the Internet use of both library visitors and staff.

This trend means that public libraries must reconsider their positions as public knowledge providers (Anttiroiko and Savolainen, 2007). As a modern librarian's task is to be able to use and distribute information in many formats other than print, he or she must be able to use all media, including digital media and social media. Associated with this, librarians are also increasingly responsible for bridging the gap between social media and end-users in a way that enables these end-users to effectively and efficiently use these media sources (Callahan, 1991). In order to accomplish these tasks of knowledge providing, librarians themselves must be proficient in social media use.

The challenge of using social media in a library context is important since it is part of a wider trend of using social media in public services and is part of the transformation towards government 2.0 (Bertot et al., 2010; Chun et al., 2010). Furthermore, it fits within a general tendency of (new) skills needed in the 21st century. These skills, i.e. communication, digital literacy, collaboration and social competencies, are identified as competencies individuals must possess in order to actively and effectively participate in the knowledge society (Voogt and Roblin, 2012).

An extensive amount of scholarly literature exists that is concerned with social media in a library context, which is mostly referred to as library 2.0 (Casey and Sevastinuk, 2006; Maness, 2006). Notwithstanding the numerous publications concerning library 2.0, the research literature reveals that social media use in the library context is still in its infancy (Anttiroiko and Savolainen, 2011). Thus far, most of the literature focusing on social media in a library context is about the potential use of social media in the library, 'how-to guides' for libraries implementing social media (Linh, 2008) and about competencies which librarians perceive as necessary to them (e.g. Huvila et al., 2013; Patridge et al., 2010). However, empirical data on actual social media implementation in libraries is still rare.

This paper contributes to the under-researched field investigating the actual implementation of social media in libraries. Previous studies have already found that successful implementation of information and communications technology (ICT) mainly depends on the librarians' ability to deal with the technology (Krissoff and Konrad, 1998). Based on this observation, we believe that successful implementation of social media in the library is associated with how proficient librarians are in social media use themselves.

Hence, this study investigates whether librarians are able to use social media effectively and efficiently to discharge their professional responsibilities as information disseminators. To refer to these abilities, we coined the term 'social media literacy' (SML), which is understood as "not only the practical and cognitive competencies possessed by users of social media but also the motivation to employ these media effectively and appropriately for social interaction and communication on the web' (Vanwynsberghe and Verdegem, 2013). The present study reports on the identification of librarians' SML profiles in Belgian public libraries.

\section{Theoretical background: The necessity of distinguishing social media literacy profiles}

\section{A conceptual framework of social media literacy}

Social media pose significant challenges for users. They encompass the quick development and constant updating of a diversity of competencies, including already-familiar reading and writing competencies and new digital competencies ranging from very basic to highly advanced. In previous literature, these competencies have been framed in terms of SML (e.g. Maier-Rabler and Huber, 2010).

Social media integrate text and visuals from print, audio-visual and broadcast media and interactivity in computing and information systems. Hence, people's engagement with social media requires a range of similar competencies needed to manage print, audio-visual and broadcast media and computing. What is new is that social media also involve competencies necessary to be able to create texts and visuals. Hence, we need a conceptual framework spanning all these competencies. The concept of SML seems to fulfil this need: it covers the interpretation of people's active participation in communicating, selecting, creating, critiquing and sharing media content on the Internet.

At the same time, we do not choose existing literacy concepts or synonyms as they have historically been tied to a particular media form or technology and consequently focus only on one or some aspects instead of considering all the competencies needed to deal with social media. We selected the term SML in order to avoid confusion with other literacy concepts. As social media converge print, audio-visual and broadcast media with computing and information systems, many of the existing concepts of literacy can indeed be applied to social media. However, it is not possible to apply the concept of SML to other kinds of media as most print, audio-visual broadcast media, computing and information systems do not provide the possibility to the users to create content themselves.

As different types of media converge with computing and information systems in social media, SML research must unite traditions in media and information literacy (Livingstone et al., 2008). We base our work on SML because all other terms used to characterize people's media 
competencies (e.g. 'digital literacy', 'cyber-literacy', 'Internet literacy', 'visual literacy') are built on one or both traditions. All these previous literacy traditions have in common 'the public's understanding of and effective engagement with media, information and communication technologies of all kinds' (Livingstone et al., 2008: 105). The question remains what the differences are between information and media literacy approaches, which are increasingly converging in social media.

One of the basic literacy competencies is the ability to read and write messages (Coiro et al., 2008). A literacy approach that has emerged from this print tradition is information literacy. This term first occurred in a report by Zurkowski (1974) on behalf of the National Commission on Libraries and Information Science. Zurkowski (1974: 6) defines 'information literacy' as the ability to utilize 'the wide range of information tools as well as primary sources in modelling information solutions to their problems'. With the rise of the Internet as a seemingly infinite source of information, the concept of information literacy gains more urgency (Sharpio and Hughes, 1996). In this respect, information literacy now includes having skills to identify an information problem (e.g. an unanswered question), accessing the location where information can be found, evaluating the information and using this information in problem-solving activities (Livingstone et al., 2005). This is a rather prescriptive and formulaic description of literacy, which is based on the assumption of a formally expressed information need. However, people do not always have an information need in advance and, for instance, may access information incidentally without looking for it. The latter is the case when people, for example, watch television or listen to the radio.

The concept of information literacy was developed in the context of print media, while the concept of media literacy originated in the context of audio-visual media. The latter literacy tradition is not based on a predefined information need and emphasizes the critical, analytic and creative competencies needed to deal with media content (Livingstone et al., 2008). Information literacy stresses the ability to access information or content, while media literacy focuses on understanding and creating the content itself. One reason for this difference is that accessing information in broadcast media has not been, until now, a significant problem (Livingstone et al., 2008). In fact, the widespread accessibility of broadcast media was what led to concerns over the power and manipulation of these media. Consequently, media literacy was framed as the ability to critically understand media messages. Information literacy instead focuses on the basic competence of locating information since information is often difficult to find or use.

The literacy concepts discussed above arose in a predigital context and then extended with the emergence of digital tools and opportunities. The presence of social media reconfigures our conceptual understanding of the



Figure I. A conceptual framework for social media literacy.

literacy concept. SML unites the different traditions of information and media literacy.

Due to the convergent and consequently complex nature of the concept of SML, a conceptual framework was created. Moreover, this framework establishes the SML measurement criteria. SML component parts and indicators, as well as the relationships between each of the elements, were determined. The framework in Figure 1 aims to conceptualize SML and is based on the discussion above. SML unifies multiple configurations of practical, cognitive and affective competencies (Vanwynsberghe and Verdegem, 2013).

Based on the information literacy tradition that acknowledges people's access to media technologies and content as a key dimension of literacy, we include practical competencies in the conceptual framework for SML. Practical competencies, or so-called button knowledge, involve handling access to, and the operation of, social media and the content on social media (Van Deursen and Van Dijk, 2009). In contrast to information literacy research, media literacy research has also paid attention to questions related to the creation of content (Livingstone et al., 2008). As social media make it easier for users to create and share content, a conceptualisation of SML must also take into account the ability to create content. Hence, practical competencies extend beyond basic functional competencies to access a technology or content such as the ability to log in, click on a link or scroll through text on various social media platforms. It also entails competencies to control interactive and creative services on social media platforms, including advanced usage such as creating and exchanging user generated content (UGC) (such as text, pictures and videos). 
Reducing SML to practical competencies would be a shortcoming. As many media and information literacy traditions have claimed, empowered media users must also acquire cognitive competencies in order to critically analyse and evaluate motives and goals that shape the media content they consume, the language of media messages and the context in which media content is produced (Potter, 2004; Share et al., 2004). Both media and information literacy traditions recognize that these cognitive competencies are also crucially linked to the online atmosphere. Print as well as audio-visual media content is produced in a context where only a few people have access to the systems of production and distribution. This pre-filtering, in accordance with criteria of political, market pressure and generally accepted norms and values, places fewer demands on the individuals' cognitive competencies for understanding and critiquing the operation and consequences of the media technologies, content and filters. In the online world, especially in social media, this distinction between producers and consumers is blurring. On social media anyone can produce and share content, with fewer and different kinds of filters. Hence, the critical cognitive competencies stressed by both media and information literacy traditions are acknowledged as an important part of SML.

Based on the work of Potter (2011) and Rogers (2003), the division most relevant to this cognitive category comprises the more critical 'how-to-knowledge' and 'whyknowledge'. This critical knowledge also involves the use of analytical logic and critical thinking and can be answered by asking questions such as 'how does something work?' and 'why does it work that way?' On the contrary, practical competencies include more 'what-knowledge' and can be described as the basic knowledge needed to access media technologies, content or services.

Factors other than practical and cognitive competencies are also related to users' individual SML (Fishbein and Ajzen, 1975; Taylor and Todd, 1995). In contrast to media and information literacy research, which has paid attention to questions of access, selection, understanding and creation, SML includes affective competencies or attitudes. Both traditions of media and information literacy risk positioning the users as a person without emotions. The final action of how people apply cognitive and practical competencies depends on how they value their own social media behaviour and the characteristics of these media. Hence, we include attitudes as a SML competence and argue that attitudes can be seen as an internal emotional state that that influences the choice of actual behaviour (Gagne, 1984).

We make a distinction between attitudes towards social media's structure, process and users. This distinction is based on McMillan and Downes' (2000) work that conceptualizes people's perception of interactivity in social media. Attitudes towards social media structure represent personal opinions on typical social media characteristics, such as creativity, interactivity and community development. Further, attitudes towards the communication process or the exchange of information on social media can also play an important role in how people act on these platforms. Drawing on Picone (2011), we posit that interactivity practices, especially in the case of social media, can also be interpreted in relation to the potential audience of an individual's content creation online. This leads us to the last attitude, namely attitudes towards social media users. It is, for example, possible that when a social media user is concerned about the reaction of other users, than he or she will not create content on these media.

The SML conceptual framework is visualized as a circle because each competence supports the others as part of a non-linear, dynamic learning process. The cognitive competencies to analyse and evaluate social media content rest on the practical competencies to open and read this content and a positive attitude towards this behaviour. Hence, profiling SML must be performed based on practical, cognitive and affective competencies.

\section{Social media literacy profiles}

Since social media are just recently being introduced in the library, librarians' actual use of social media and their corresponding social media literacy profiles are largely neglected in scholarly literature. Consequently, we mainly rely on media and information literacy literature to understand how librarians have been classified concerning their competencies to use other kinds of technologies.

Several studies have been conducted to examine the media and information literacy levels of different social groups such as scholars, students, teachers and professionals (Gibson et al., 2007; Livingstone et al., 2005; Majid and Abazova, 1999). Moreover, some studies have already described media and information literacy profiles. Paulussen et al. (2011), for instance, distinguished three digital media profiles in the overall Flemish population: (1) advanced; (2) skilled; and (3) limited digital media users. This division was based on the skills or practical competencies of people, considering whether members of the population were able to use search machines, copy files and install computer programs. Concerning information literacy, Kiili et al. (2008) identified five profiles based on students' evaluation of Internet sources: (1) versatile evaluators; (2) relevance-orientated evaluators; (3) limited evaluators; (4) disorientated readers; and (5) uncritical readers. The students in this study were asked to write an essay and verbalize their thoughts during the material-gathering process on the Internet.

Research investigating librarians' media and information literacy and their related profiles, however, remains relatively scarce. Only a few studies have focused on librarians' media and information literacy (Adeyoyin, 
2005, 2006; Adomi and Anie, 2006; Black et al., 2001; Majid and Abazova, 1999; Safahieh and Asefeh, 2010; Simmons, 2005). The studies that focus on information literacy in libraries investigate how librarians could play a role in teaching information literacy. Korobili et al. (2008), for example, identified profiles emphasizing teaching abilities, pedagogical experience, infrastructure and funding. On the other hand, the media literacy studies mainly focused on how well librarians were able to use computer and Internet application. For example, Adeyoyin (2005, 2006) made a distinction between ICT-literate and ICTilliterate librarians. The existing studies on media and information literacy profiles focus primarily on the practical competencies needed to deal with media technologies; cognitive and affective competencies have so far been neglected.

Concerning librarians' SML, a number of studies exist that have empirically identified key competencies that librarians perceived they need in the current social media culture (e.g. Huvila et al., 2013; Patridge et al., 2010). However, these studies do not examine librarians' actual social media use and their corresponding profiles. Insight into these profiles is important for its relevance to academic research on librarians and as input for social media training in libraries.

\section{Method and research context}

\section{Research context}

This study is part of a research project funded by the Flemish Government. It emerged out of workshops offered with the goal of increasing the social media knowledge and skills of professionals working with young people, such as librarians, teachers and youth workers. We focus in this study on libraries because they are, as other research has shown, attempting to implement social media (e.g. Casey and Sevastinuk, 2006; Linh, 2008; Maness, 2006). In order to investigate whether and which librarians are able to use social media effectively and efficiently to discharge their professional responsibilities, we developed an SML typology within the present study.

\section{Participants}

Six Flemish public libraries that participated in the workshops also contributed to this research. In order to investigate librarians' SML profiles, an online questionnaire was constructed. This online survey was administered to 258 librarians at the libraries that participated in the workshops. Prior to each survey, a consent form was delivered to the libraries' management. Before conducting the survey, we explained to the librarians that their responses would be anonymous. In all, 219 librarians filled out the questionnaire, yielding a response rate of $77.46 \%$.

\section{Analysis method}

The typology is based on the findings of the online survey. Data were transformed from the Qualtrics survey software program to an SPSS 17.0 data file. Exploratory factor analysis using maximum likelihood with direct oblimin rotation (Kaiser normalization) was performed on the data. Through these analyses, competence scales identifying SML were constructed. Thereafter, a cluster analysis was used to identify librarians sharing a common SML profile. We used SML factors such as frequency and place of social media use, social media competencies, knowledge about social media and attitudes towards social media. In order to detect SML profiles, a k-means cluster analysis was conducted. However, to identify the appropriate number of clusters (k), we first conducted a hierarchical cluster analysis on the SML factors (Janssens et al., 2008).

\section{Measurements}

Social media use was measured by asking the respondents how often they connected to social media during their work and leisure time. Responses were measured using a five-point scale ranging from 'never' to 'several times a day'. In addition, we asked the respondents for what purposes they used social media for on the work floor. Multiple answers were possible, ranging from communicating for work-related or private purposes to searching or sharing information for work-related or private purposes. In the questionnaire, social media were defined as blogs, social networking sites, wikis, collaborative tagging sites and sites enabling the sharing of content.

Practical and cognitive competencies were determined based on how well the respondents evaluated their performance of social media activities. Simultaneously, we took into account the frequency of use of these activities. Hence, higher self-efficacy in performing these activities and more frequent usage was correlated to more advanced practical and cognitive competencies. We multiplied the self-efficacy measure with the frequency measure and treated the outcome as one variable. Exploratory factor analysis (maximum-likelihood estimation with varimax rotation) revealed two factors, which we labelled as practical and cognitive competencies.

Our practical competence scale consists of nine items $(\alpha=0.94)$. With these practical competencies, we refer to, for instance, being able to upload pictures, tag photos and comment on social media. The cognitive competence scale contains four items $(\alpha=0.91)$. These competencies are related to, for instance, checking if the information in a social media message is still up to date, thinking about the context wherein content on social media is produced and evaluating if the information on social media is correct or useful. Raw scores consisting of higher values indicated higher competency levels. 
Table I. K-means cluster analysis on centred variables $(* p<0.05, * * *<0.001)$.

\begin{tabular}{|c|c|c|c|c|c|c|c|}
\hline & & $\begin{array}{l}\text { Worker } \\
(23.37 \%)\end{array}$ & $\begin{array}{l}\text { Laggard } \\
(23.91 \%)\end{array}$ & $\begin{array}{l}\text { Literate } \\
(28.26 \%)\end{array}$ & $\begin{array}{l}\text { Spare-time user } \\
(24.46 \%)\end{array}$ & $\begin{array}{l}\text { Mean square } \\
\text { clusters }\end{array}$ & F-value \\
\hline \multicolumn{2}{|c|}{ Attitudes } & 3.52 & 2.86 & 4.18 & 3.65 & 13.97 & $44.47 * * *$ \\
\hline \multicolumn{2}{|c|}{ Knowledge } & 2.27 & 2.03 & 3.54 & 2.76 & 21.67 & $37.91 * * *$ \\
\hline \multicolumn{2}{|c|}{ Use of social media: at home } & 3.49 & 1.43 & 4.83 & 4.33 & 103.26 & 187.79*** \\
\hline \multicolumn{2}{|c|}{ Use of social media: at work } & 3.77 & 1.23 & 4.56 & 1.42 & $|3| .7 \mid$ & $375.09 * * *$ \\
\hline \multicolumn{2}{|c|}{ Technological competence } & 0.12 & 0.00 & 0.83 & 0.38 & 6.63 & $29.51 * * *$ \\
\hline \multicolumn{2}{|c|}{ Cognitive competence } & 0.16 & 0.02 & 0.92 & 0.29 & 7.78 & $37.91 * * *$ \\
\hline \multirow[t]{2}{*}{ Gender $^{\mathrm{a}}$} & Male & $25.60 \%$ & $15.90 \%$ & $42.30 \%$ & $24.40 \%$ & & \\
\hline & Female & $74.40 \%$ & $84.10 \%$ & $57.70 \%$ & $75.60 \%$ & & \\
\hline \multicolumn{2}{|c|}{$\begin{array}{l}\text { Average age } \\
\text { (SD) }\end{array}$} & $\begin{array}{l}49 \\
(8.7 I)\end{array}$ & $\begin{array}{l}50 \\
(8.16)\end{array}$ & $\begin{array}{l}40 \\
(9.53)\end{array}$ & $\begin{array}{l}44 \\
(9.97)\end{array}$ & & \\
\hline
\end{tabular}

aDescriptive socio-demographic statistics of respondents' corresponding social media cluster.

Related to these practical competencies and cognitive competencies, which focus on skills, we also considered a measure of social media knowledge. Based on Hargittai (2009), we asked respondents about their familiarity with certain terms related to social media use, such as tagging, cookies and social bookmarking. Responses were measured using 'yes' or 'no' answers. Raw scores consisting of higher values indicated higher SML levels.

SML also contains affective competencies, which we measured as attitudes based on a series of items proposed by Bruner et al. (2001). The measure of attitudes contains an established seven-item, five-point semantic differential scale (bad/good, foolish/clever, unpleasant/pleasant, useless/useful, boring/interesting and negative/positive). This way, we can take into account respondents' attitudes towards social media's structure, process and users with one question. Factor analysis (varimax rotation) revealed a single factor, which we named social media attitudes $(\alpha=$ 0.94). Raw scores consisting of higher values indicated positive attitudes towards social media.

More specifications about the measurements can be found in Appendix 1.

\section{Results}

\section{Respondent characteristics}

The librarian sample consisted of 161 females (73.5\%) and 58 males $(26.5 \%)$ with a mean age of 46.28 years (ranging from 24 to 63 years; $\mathrm{SD}=9.75$ ). Of the respondents, $34.20 \%$ used social media in their spare time on a daily basis, $22.80 \%$ weekly, $21.40 \%$ monthly and $21.50 \%$ never. The proportion of librarians who used social media in the work context every day was lower (16.60\%). In addition, $18.30 \%$ used social media in the work context on a weekly basis, $24.70 \%$ monthly and $37.40 \%$ never. The mean of librarians' practical and cognitive competencies was very low; the scores were 0.32 and 0.34 on a five-point scale, respectively (SD practical competencies: 0.50; SD cognitive competencies: 0.60 ). The respondents' average score on the social media knowledge variable was a bit higher than the average score on practical and cognitive competencies; this score was 2.65 (SD knowledge: 0.98 ) on a five-point scale. The librarians' mean score on affective competencies was 3.55 (SD affective competencies) on a five-point scale. More than half the respondents used social media at least once a week in their free time, while less than half used it at least once a week in the work context. On average, the respondents had positive attitudes towards the use of social media; however, they did not have sufficient knowledge and skills.

\section{A typology of four social media profiles}

The dendogram in the hierarchical cluster analysis, obtained using Ward's method of linkage and squared Euclidean distances, revealed peaks at four and five clusters. A k-means cluster analysis was then conducted to examine four and five cluster solutions. Our typology containing four clusters was the most information-rich and interpretable. Table 1 provides an overview of these four clusters and their main characteristics.

The first cluster contains librarians who have, on average, higher social media use at work than at home. Therefore, we call this cluster the social media workers. This cluster corresponds to librarians with a relatively positive attitude towards social media. On the other hand, this cluster scores relatively low on knowledge about social media and on the practical and cognitive competencies required to use social media. Of the survey respondents, $23.37 \%$ fit within the social media workers cluster. Respondents within this social media worker profile have a high probability of being female and predominantly belong to older age groups.

The second cluster consists of respondents who have the lowest score for SML factors and consequently are labelled social media laggards. This SML profile 
Table 2. Comparing the social media literacy profiles on their use of social media in the library $(* p<0.05, * * *<0.001)$.

\begin{tabular}{lccccc}
\hline & Worker & Laggard & Literate & Spare-time user & Sig. \\
\hline $\begin{array}{l}\text { The use of social media in the library for } \\
\text { communicating with colleagues }\end{array}$ & $34.90 \%$ & $4.50 \%$ & $34.60 \%$ & $6.70 \%$ & $* * * *$ \\
$\quad$... For communicating with library visitors & $30.20 \%$ & $2.30 \%$ & $57.70 \%$ & $2.20 \%$ & $* * *$ \\
$\quad$... Communicating with friends & $4.70 \%$ & $0.00 \%$ & $15.40 \%$ & $0.00 \%$ & $/$ \\
...For searching work-related information & $74.40 \%$ & $9.10 \%$ & $86.50 \%$ & $33.30 \%$ & $* * *$ \\
$\quad$...For sharing work-related information with others & $30.20 \%$ & $4.50 \%$ & $63.50 \%$ & $8.90 \%$ & $* * *$ \\
$\quad$...For searching private information & $14.00 \%$ & $0.00 \%$ & $13.50 \%$ & $2.20 \%$ & $/$ \\
$\quad$...For sharing private information with others & $7.00 \%$ & $0.00 \%$ & $9.60 \%$ & $0.00 \%$ & $/$ \\
\hline
\end{tabular}

corresponds to people who have a rather negative attitude towards social media and do not (often) use social media at work or at home. Furthermore, social media laggards also have a very low level of social media knowledge and competencies. Of the respondents, $23.91 \%$ belong to this cluster; they have a high probability of being female and predominantly belong to older age groups.

The third cluster is the most social media literate group; therefore, we label respondents who fit within this cluster, social media literate users. This cluster consists of respondents who use social media often at work and at home. They also have the most positive attitude towards social media and are characterized by the highest level of SML knowledge and competencies. Most of the librarians (28.26\%) belong to this cluster. Though its members are usually female, this social media literate cluster contains the most men in comparison to the other clusters. The members of this cluster are situated in the younger age groups.

The fourth cluster contains respondents who use social media more often in their spare time than at work. Hence, we name respondents in this cluster, social media sparetime users. These respondents have a positive attitude towards social media. They use social media at work but not as much as at home. These respondents also have a relatively high level of SML knowledge and competencies. Of the librarians in this research, $24.46 \%$ are social media spare-time users. Spare-time users are predominantly female and belong to younger age groups.

In order to verify these findings, we conducted an analysis of variance (ANOVA) on the survey data concerning the use of social media among the librarians. We only found significant differences for the work-related use of social media among the librarians and not with regard to private use. The results of the ANOVA, shown in Table 2, confirmed that social media literates and social media workers use social media more often for communicating with colleagues and potential library visitors. This also involves searching work-related information and sharing this information with others. Social media literates and social media workers use social media more to perform work-related activities than the other two profiles, namely social media laggards and spare-time users. Hence, social media literates and social media workers include librarians who can serve as facilitators or agents to guide and support other librarians during social media implementation.

\section{Conclusion}

Since libraries play a mediating role in the transfer of information and social media are increasingly becoming a tool to gather this information (Anttiroiko and Savolainen, 2007), we focused on the adoption and implementation of social media in the library in this study. The aim of this study was to identify public librarians' SML profiles. Our findings add to the current literature on SML in several respects.

First, we developed and measured the SML concept in this study. The conceptualization and measurement instrument examines three competencies: practical, cognitive and affective social media competencies. As there is little consensus among scholars about how these competencies should be defined, we conceptualized and operationalized each of these competencies. Practical competencies were defined as the access to and operation of social media, or so-called 'button knowledge'. We defined cognitive competencies as the critical analysis and evaluation of motives and goals shaping the consumed content, the language of messages and the context in which content is produced. Finally, affective competencies are the attitudes towards or evaluation of social media characteristics and social media behaviour.

Second, based on these competencies, we were able to identify four SML profiles: social media workers, social media laggards, social media literates and social media spare-time users. Social media workers are librarians who use social media mostly in the library and have a relatively high level of SML. Social media laggards do not use social media frequently either at home or at work and have a low level of SML. The social media literates are librarians who frequently use social media at home and at work and have a high level of SML. Finally, social media spare-time users are librarians who frequently use social media at home but not in the library and have an average level of SML.

This division is almost parallel with previous research on ICT profiles (Paulussen et al., 2011), including ICT 
profiles of librarians (Adeyoyin, 2005, 2006). Each of these studies found a group of advanced users, or literates, and a group of non-users, or illiterates. By adding the context of social media use, we were able to identify more profiles. The latter provides an important nuance regarding social media implementation in libraries.

This typology provides insight into the distribution of SML among librarians. The librarians were almost equally divided into the four SML profiles, though most librarians fit into the social media literate profile, followed by the social media spare-time users and social media workers. The smallest group was the cluster of the social media laggards. The latter indicates that social media are becoming more important and popular in everyday life and in the work context of library staff, which has been indicated in previous research (Huvila et al., 2013; Patridge et al., 2010).

Since social media literates and social media workers effectively and efficiently use social media to discharge their professional responsibilities, librarians who fit these profiles can serve as facilitators or agents to guide and support other librarians during social media implementation in their organisations. As previous studies found that successful implementation of ICT mainly depends on librarians' ability to use the technology (Krissoff and Konrad, 1998), we believe that in Flanders the conditions are in place to adapt and implement social media in libraries.

\section{Limitations and future research directions}

This study tracked the distribution of SML profiles and provided an organized, representative framework to provide more information about how the profiles can be positioned towards each other. Further research could use the measurement tools constructed in the present study that reflect the SML profiles taken on by librarians in practice. This profiling can be used in social media training to identify the strengths and weaknesses of different librarians. A librarian could be provided specific training based on the librarian's corresponding profile. For example, social media workers and social media spare-time users could both be given training on the personal and professional benefits of using social media, while social media laggards could benefit from comprehensive training on how to use social media in a personal and professional context. Social media literates could be appointed trainers for the other profiles.

The four profiles identified in this study could also be used in social network analysis. In this respect, the relation between having a particular profile and the social media implementation in libraries could be further examined. This way, we could enhance our understanding of how colleagues with different profiles distribute their knowledge and skills within the library. Additionally, longitudinal research could use this typology to determine how librarians' SML profiles evolve. Such data would be useful for the development of library policies.

The typology of social media users in libraries as presented in this study needs further refinement and evaluation. In this study, we measured respondents' actual competencies based on their self-perceived competencies. This measurement method has the ability to present a large number of questions on a wide range of competencies to a large number of respondents in a short time. However, self-perceived competencies are always perspective- and context-dependent (Talja, 2005). Talja (2005) notes that an individual's perception of his/her competencies depends upon with whom they compare themselves. Hence, it would be useful in further research to identify librarians' actual social media competencies using performance tests (Van Deursen and Van Dijk, 2010) and to compare these with the self-perceived competencies measured in this study. Findings should also be validated within libraries and samples other than Flanders. Notwithstanding these limitations, we believe that the typology of this study could be used to further clarify issues surrounding the adoption and implementation of social media in libraries.

\section{Funding}

This research is conducted within the EMSOC - User Empowerment in a Social Media Culture - project, funded by the government agency for Innovation by Science and Technology (IWT, SBO programme) in Flanders, Belgium.

\section{References}

Adeyoyin SO (2005) Information and communication technology (ICT) literacy among the staff of Nigerian university libraries. Library Review 54(4): 257-266.

Adeyoyin SO (2006) ICT literacy among the staff of West African university libraries: A comparative study of anglophone and francophone countries. Electronic Library 24(5): 694-705.

Adomi EE and Anie SO (2006) An assessment of computer literacy skills of professionals in Nigerian university libraries. Library Hi Tech 23(2): 10-14.

Anttiroiko A and Savolainen R (2007) New premises of public library strategies in the age of globalization. In: Garten ED, Williams DE, Nyce JM, et al. (eds) Advances in Library Administration and Organization. Amsterdam: Elsevier, JAI Press, pp. 61-81.

Anttiroiko A and Savolainen R (2011) Towards library 2.0: The adoption of web 2.0 technologies in public libraries. International Journal of Libraries and Information Services 61(2): 87-99.

Bechmann A and Lomborg S (2013) Mapping actor roles in social media: Different perspectives on value creation in theories of user participation. New Media \& Society 15(5): 765-781.

Bertot JC, Jaeger PT and Grimes JM (2010) Using ICTs to create a culture of transparency: E-government and social 
media as openness and anti-corruption tools for societies. Government Information Quarterly 27(3): 264-271.

Black C, Crest S and Volland M (2001) Building a successful information literacy infrastructure on the foundation of librarian-faculty collaboration. Research Strategies 18(3): 215-225.

Bruner GC, James KE and Hensel PJ (2001) Marketing Scales Handbook. Chicago, IL: American Marketing Association.

Bruns A (2008) Blogs, Wikipedia, Second Life, and Beyond: From Production to Produsage. New York: Peter Lang.

Callahan DR (1991) The librarian as change agent in the diffusion of technological innovation. Electronic Library 9(1): $13-15$.

Casey ME and Sevastinuk LC (2006) Library 2.0: Service for the next-generation library. Library Journal 131(14): 40-42.

Chun SA, Shulman S, Sandoval R, et al. (2010) Government 2.0: Making connections between citizens, data and government. Information Polity 15(1/2): 1-9.

Coiro J, Knobel M, Lankshear C, et al. (2008) Central issues in new literacies and new literacies research. In: Coiro J, Knobel M, Lankshear C and et al. (eds) Handbook of Research on NewLiteracies. New York: Lawrence Erlbaum, pp. 1-21.

Fishbein M and Ajzen I (1975) Belief, Attitude, Intention and Behavior: An Introduction to Theory and Research. Reading, MA: Addison-Wesley.

Gagne RM (1984) Learning outcomes and their effects: Useful categories of human performance. American Psychologist 39(4): 377-385.

Gibson J, Jack K and Rennie JS (2007) Computer literacy, skills and knowledge among dentists and professionals complementary to dentistry in Scotland. Health Informatics Journal 13(4): 267-282.

Hargittai E (2009) An update on survey measures of web-oriented digital literacy. Social Science Computer Review 27(1): 130-137.

Huvila I, Holmberg K, Kronqvist-Berg M, et al. (2013) What is Librarian 2.0 - New competencies or interactive relations? A library professional viewpoint. Journal of Librarianship and Information Science 45(4): 198-205.

Janssens W, Wijnen K, Pelsmacker P, et al. (2008) Marketing Research with SPSS. London: Pearson Education.

Jenkins H (2006) Convergence Culture: Where Old and New Media Collide. New York: New York University Press.

Kiili C, Laurinen L and Marttunen M (2008) Students evaluating Internet sources: From versatile evaluators to uncritical readers. Journal of Educational Computing Research 39(1): 75-95.

Korobili S, Malliari A and Christodoulou G (2008) Information literacy paradigm in academic libraries in Greece and Cyprus. Reference Services Review 36(2): 180-193.

Krissoff A and Konrad L (1998) Computer training for staff and patrons. Computers in Libraries 18(1): 30-32.

Linh NC (2008) A survey of the application of web 2.0 in Australian university libraries. Library Hi Tech 26(4): 630-653.

Livingstone S, Van Couvering E and Thumim N (2005) Adult Media Literacy: A Review of the Research Literature. London: Office of Communications (Ofcom).

Livingstone S, Van Couvering E and Thumin N (2008) Converging traditions of research on media and information literacies:
Disciplinary, critical, and methodological issues. In: Coiro J, Knobel M, Lankshear C, et al. (eds) Handbook of Research on New Literacies. New York: Routledge, pp. 103-132.

McMillan SJ and Downes EJ (2000) Defining interactivity: A qualitative identification of key dimensions. New Media \& Society 2(2): 157-179.

Maier-Rabler U and Huber S (2010) Sustainable e-participation through participatory experiences in education. eJournal of eDemocracy \& Open Government 2(2): 131-144.

Majid SH and Abazova AF (1999) Computer literacy and use of electronic information sources by academics: A case study of Internatinal Islamic University of Malaysia. Asian Libraries 8(4): 100-111.

Maness JM (2006) Library 2.0 theory: Web 2.0 and its implications for libraries. Webology 3(2): Article 25.

Patridge H, Lee JJ and Munro C (2010) Becoming 'Librarian 2.0': The skills, knowledge, and attributes required by library and information science professionals in a web 2.0 world (and beyond). Library Trends 59(1/2): 315-335.

Paulussen S, Courtois C, Vanwynsberghe H, et al. (2011) Profielen van mediageletterdheid: Een exploratie van de digitale vaardigheden van burgers in Vlaanderen. In: Moreas $\mathrm{M}$ and Pickery J (eds) Mediageletterdheid in een Digitale Wereld. Sint-Pieters-Leeuw: Claes Printing, pp. 61-76.

Picone I (2011) Produsage as a form of self-publication: A qualitative study of casual news produsage. New Review of Hypermedia and Multimedia 17(1): 99-120.

Potter J (2004) Theory of Media Literacy: A Cognitive Approach. Thousand Oaks, CA: SAGE.

Potter J (2011) Media Literacy. 5th edn. Thousand Oaks, CA: SAGE.

Rogers EM (2003) Diffusion of Innovations. 5th edn. New York: The Free Press.

Safahieh H and Asefeh A (2010) Computer literacy skills of librarians: A case study of Isfahan University libraries, Iran. Electronic Library 28(1): 89-99.

Share J, Jolls T and Thoman E (2004) Five Key Questions that Can Change the World. Santa Monica, CA: Center for Media Literacy.

Sharpio JJ and Hughes SK (1996) Information literacy as a liberal art: Enlightenment proposals for a new curriculum. Educom Review 31(2): 31-35.

Simmons MH (2005) Librarians as disciplinary discourse mediators: Using genre theory to move toward critical information literacy. Libraries and the Academy 5(3): 297-311.

Talja S (2005) The social and discursive construction of computing skills. Journal of the American Society for Information Science and Technology 56(1): 13-22.

Taylor S and Todd P (1995) Decomposition and crossover effects in the theory of planned behavior: A study of consumer adoption intentions. International Journal of Research in Marketing 12(2): 137-155.

van Deursen A and van Dijk J (2009) Improving digital skills for the use of online public information and services. Government Information Quarterly 26: 333-340.

van Deursen A and van Dijk J (2010) Measuring Internet skills. International Journal of Human-Computer Interaction 26(10): 891-916.

Vanwynsberghe H and Verdegem P (2013). Integrating social media in education. ClCWeb-Comparative Literature and Culture 15(3): Article 10. 
Voogt J and Roblin NP (2012) A comparative analysis of international frameworks for 21 st century competences: Implications for national curriculum policies. Journal of Curriculum Studies 44(3): 299-321.

Zurkowski PG (1974) The Information Service Environment: Relationships and Priorities. Washington, DC: National Commission on Libraries and Information Science.

\section{Author biographies}

Hadewijch Vanwynsberghe is working towards her $\mathrm{PhD}$ in Communication Sciences at Ghent University on the measuring of (new) media literacy in the converging information society. She is affiliated with the iMinds Research Group for Media \& ICT (iMinds-MICT). Her fields of interests include the measurement of (social) media literacy, social media and digital inclusion. Vanwynsberghe's recent publications include - with Pieter Verdegem - (2013) Integrating social media in education. ClCWeb-Comparative Literature and Culture 15(3): Article 10.

Ruben Vanderlinde is an assistant professor and postdoctoral researcher (Research Foundation Flanders - FWO) at the Department of Educational Studies at Ghent University in Belgium. His research interests are in the field of educational innovation, teacher training and professionalization, and the integration of Information and Communication Technologies (ICT) in education. He publishes widely on these topics, both in ISI listed journals and more practitioner-oriented journals. He teaches 'Educational Innovation' and 'Pedagogy of Teaching' on the Bachelors and Masters of Educational Sciences courses (Ghent University). Dr Ruben Vanderlinde is methodologically experienced in mixed method research, and currently a member of the EAPRIL-board (European Association for Practitioner Research on Improving Learning). He is a visiting research scholar at the Curry School of Education (University of Virginia), and at the 'Internet Interdisciplinary Institute' of the Open University of Catalonia (Barcelona).

Annabel Georges graduated in 2013 as Master in Communication Sciences (specialization 'New Media and Society') at Ghent University. In her Master's thesis Social media from A to Z: The role of media coaches in the diffusion of social media literacy, within the library as organization she used social network analysis to study the diffusion of social media literacy within the library. In August 2013 Annabel started at the iMinds Research Group for Media \& ICT (iMinds-MICT) as a Junior Researcher.

Pieter Verdegem is an assistant professor (Tenure Track - BOF ZAP) in New Media and Information \& Communication Technologies in the Department of Communication Sciences at Ghent University. He is also affiliated with the iMinds Research Group for Media \& ICT (iMinds-MICT). His main research interests are in ICT and society, social media, new media \& ICT policies and governance. He has published widely on these topics in scholarly journals. He teaches 'New Media Studies' on the MA programme and Media Structures \& Media Policy on the BA level.

\section{Appendix I: Survey}

Gender: $\quad$ Gender? Male/Female

Age: $\quad$ Year of birth?

Knowledge: Which of the following concepts do you know? Y/N

Terms: $\quad$ Wall, Sharing, Status, Torrent, Social networking, Profile, Cookie, Like, Phishing, Social bookmarking, Rating, Commenting, Malware, Widget, Social reading or None of the above.

\section{Social media use}

How often do you use social media in your spare time? 1) Never, 2) Less than once a month, 3) Once or twice a month, 4) Once or twice a week, 5) Every day or almost every day or 6) Several times a day.

How often do you use social media in your spare time? 1) Never, 2) Less once a month, 3) Once or twice a month, 4) Once or twice a week, 5) Every day or almost every day or 6) Several times a day.

For what purpose do you use social media at work (multiple answers possible)? To communicate with colleagues, Communicate with library visitors, Communicate with friends, Search for work-related information, Share work-related information, Search for private information or Share private information.

\section{Attitudes}

Social media are ... On a scale of 1) to 5): bad-good, foolish-clever, unpleasant-pleasant, useless-useful, boring-interesting and negative-positive

\section{Practical and cognitive competencies}

How good do you think you are in performing the following activities on Facebook? 1) I cannot do this at all - 5) I'm very good at this

How often do you perform these activities on Facebook? 1) Never, 2) Less than once a month, 3) Once or twice a month, 4) Once or twice a week, 5) Every day or almost every day or 6) Several times a day. 


\section{Activities}

- Uploading your own pictures;

- Consulting statistics on a social media website;

- Liking a picture/video/message;

- Posting a review (for example of a book) on a social media website;

- Tagging a photo;

- Searching for information (about, for example, a book) via social media;

- Creating a poll/quiz/questionnaire on social media;

- Determining whether an author of a particular message on social media has the authority to make certain statements;

- Determining whether information on social media is sufficiently up-to-date;

- Combining a custom message on social media with a link to another website;

- Making a message on a social media website in such a way that you certainly get a response (in the form of texts/'likes');

- Responding to others' input on social media (in the form of texts/ 'likes');

- Combining your own text message on social media with images (photos or links to videos);

- Analysing the context in which a message, photo or video on a social media website is written or created. 